\title{
MAQASID AL SHARI'AH DALAM KEUANGAN ISLAM (TINJAUAN TEORITIS ATAS PEMIKIRAN DR AHCENE LAHSASNA)
}

\author{
Muhammad Deni Putra \\ IAIN Batusangkar \\ shariaeconomic.uii@gmail.com
}

\begin{abstract}
Abstrak
Dr Ahcene Lahsasna menyampaikan resolusi untuk perbankan Islam berdasarkan konsep maqasid al syariah yang dikeluarkan oleh Shari'ah Advisory Council (SAC). Dr Ahcene Lahsasna sepertinya ingin memberikan sebuah penguatan pemahaman bahwa Islam melalui maqasid al syariah mampu diaplikasikan dan akan menghasilkan kebaikan yang istimewa. Maqasid al syariah merupakan aspek penting dalam pengembangan hukum Islam. Ini sekaligus sebagai jawaban bahwa hukum Islam itu dapat dan bahkan sangat mungkin beradaptasi dengan perubahan-perubahan sosial yang terjadi di masyarakat.Namun Maqasid al syariah (dalam Ushul Fiqh tradisional) selalu dianggap sebagai ilmu pelengkap, bukan sebagai sebuah disiplin ilmu yang independen dalam menetapkan suatu hukum. Dalam hal ini, Dr Ahcene Lahsasna mencoba menerapkan maqasid al syariah untuk menetapkan berbagai ketentuan dalam konsep mengenai keuangan Islam.
\end{abstract}

Kata Kunci: Abcene Lahasna, Maqasid al Syariah, Kenangan Islam

\section{PENDAHULUAN}

Dr. Ahcene Lahsasna berpendapat bahwa maqasid al syariah merupakan konsep yang paling penting dalam memperkuat konsep keuangan Islam saat ini. Hal ini ditujukan agar kegiatan lembaga keuangan Islam dapat melaksanakan konsep syariah. Untuk itu diperlukan pemahaman yang tepat berkaitan dengan konsep, fitur, prinsip dan kategori dari maqasid syariah guna dapat diimplementasikan ${ }^{1}$. Barangkali hal ini mirip dengan yang diinginkan oleh Kuntowijoyo dengan lima program reinterpretasi terutama program ketiga yaitu

${ }^{1}$ Ahcene Lahsasna, Maqasid Al Shari'ah In Islamic Finance, hlm. xix 
mengubah Islam yang normatif menjadi teoritis ${ }^{2}$. Dengan begitu, konsep syariah mampu menjadi teori yang bisa dilaksanakan, terutama dalam bidang keuangan.

Dalam kajian buku ini, disampaikan bahwa inti dari teori maqasid al syariah adalah maslabah ${ }^{3}$. Tentunya dengan maslahah maka konsep keuangan Islam akan bertujuan untuk mewujudkan kepentingan publik. maslahah memberikan pemihakannya tidak saja pada individu, tetapi juga kepentingan masyarakat yang lebih luas. Dengan berorientasi pada maslahah, kehidupan dapat menciptakan masyarakat yang adil dan makmur yangmempunyai implikasi jauh, tidak saja dalam konteks materil-duniawi, tetapi juga spiritual-ukhrawi ${ }^{4}$.

Alasan menggunakan maqasid al syariah untuk digunakan dalam membahas konsep keuangan dalam Islam adalah ${ }^{5}$ :

1. Maqasid al syariah dapat digunakan untuk menetapkan parameter maslahah dan mafsadah.

2. Maqasid al syariah memungkinkan untuk memahami berbagai tingkatan, tujuan syariah, prioritas dan kategorinya.

3. Maqasid al syariah juga meneliti hubungan antara dua jenis maqasid dimana maqasid mukallaf harus patuh kepada maqasid dari pemberi hukum untuk memastikan konsistensi dan kepatuhan syariah dalam kegiatan manusia.

4. Maqasid al syariah memfasilitasi proses penalaran hukum muamalah untuk bisa diterapkan.

5. Penalaran dalam maqasid al syariabmenjadi pintu gerbang analogi dimana putusan syariah dapat diperluas untuk kasus lain berdasarkan penyebabnya.

6. Maqasid al syariah memainkan peran penting untuk digunakan sebagai parameter dalam menilai hadist ahad.

\footnotetext{
${ }^{2}$ Kuntowijoyo, Paradigma Islam Reinterpretasi Untuk Aksi, hlm.284

3 Ahcene Lahsasna, Maqasid Al Shari'ah In Islamic Finance, hlm. xix

4 Dede Nurrohman, konsep self-interest dan maslahah dalam rasionalitas ekonomi islam, ISLAMICA, Vol. 5, No. 1, September 2010

5 Ahcene Lahsasna, Maqasid Al Shari'ah In Islamic Finance, hlm. xxii-xxiv
} 
7. Maqasid al syariah telah dianggap sebagai pedoman umum dan parameter untuk mengeluarkan resolusi yang tepat bagi ulama dalam melaksanakan ijtibad.

8. Maqasid al syariah dapat digunakan untuk menentukan makna dari ketentuan Al Qur'an dan sunnah.

9. Hubungan yang kuat antara Maqasid al syariah, kaidah-kaidah fiqh dan kaidah yurisprudensi Islam membuat Maqasid al syariah sebagai disiplin makro yang menghubungkan dengan disiplin lain dalam ilmu pengetahuan Islam.

Buku ini melakukan pembahasan Maqasid al syariah dalam keuangan Islam dengan dua pendekatan. Pendekatan pertama adalah pendekatan makro ketika fokusnya berupa tujuan umum syariah dari kekayaan, properti, bisnis dan keuangan. Pendekatan kedua adalah pendekatan mikro yang memfokuskan pada tujuan aplikasi, produk, instrument, dan layanan yang ditawarkan dalam keuangan Islam ${ }^{6}$ Dalam memaparkan konsepnya, Dr. Ahcene Lahsasna membagi bukunya dalam 10 bab. Bab 1 berisi pengantar konsep maqasid al syariah, bab 2 membahas tentang maqasid al syariah dan doktrin maslahah, bab 3 membahas tentang maqasid al syariah dan kekayaan, bab 4 membahas tentang maqasid al syariah dalam ekonomi dan keuangan Islam dengan pendekatan umum, bab 5 membahas tentang maqasid al syariah dalam ekonomi dan keuangan Islam dengan pendekatan khusus, bab 6 membahas tentang mekanisme pelaksanaan maqasid al syariah dalam bisnis dan keuangan, bab 7 membahas tentang maqasid al syariah dan kaidah fiqh, bab 8 membahas tentang bentuk dan substansi maqasid al syariah dan implikasinya dalam aplikasi keuangan Islam, bab 9 membahas tentang etika, maqasid al syariah dan keuangan Islam, bab 10 membahas tentang resolusi untuk perbankkan dan keuangan Islam berdasarkan maqasid al syariah.

Buku ini mencoba untuk menyoroti tujuan berikut ${ }^{7}$ : 
1. Menjelaskan konsep maqasid al syariah sebagai bidang penting dari pengetahuan tentang syariah dan keuangan Islam.

2. Menjelaskan tentang doktrin maslahah dan arti pentingnya dalam teori maqasid al syariah.

3. Menjelaskan konsep kekayaan dan siklusnya dari perspektif maqasid al syariah.

4. Menjelaskan maqasid al syariah dalam bidang ekonomi dan keuangan Islam berdasarkan pendekatan umum.

5. Menjelaskan maqasid al syariah dalam bidang ekonomi dan keuangan Islam berdasarkan pendekatan khusus.

6. Memperlihatkan mekanisme implementasi maqasid al syariah dalam bisnis dan keuangan.

7. Membahas masalah bentuk dan substansi maqasid al syariah dan menunjukkan implikasinya dalam aplikasi keuangan Islam.

8. Membahas pentingnya etika dari perspektif maqasid al syariah dalam bidang keuangan Islam.

\section{KONSEP MAQASID AL SYARIAH DR. AHCENE LAHSASNA}

Dr. Ahcene Lahsasna mengambil definisi maqasid al syariah dari Ibnu Ashur yang mendefinisikan maqasid al syariah berdasarkan dua aspek. Yang pertama adalah aspek umum yang merupakan tujuan dan hikmah di balik diberlakukannya semua atau sebagian dari putusan syariah. Yang kedua adalah berhubungan dengan maksud tertentu untuk tujuan-tujuan yang dirancang guna mencapai manfaat khusus bagi manusia dalam kehidupan sehari-hari mereka, seperti keuangan Islam ${ }^{8}$.

Berikutnya menurut Alal Al Fasi, maqasid al syariah adalah Tujuan yang dikehendaki syariat dan rahasia-rahasia yang ditetapkan oleh syariat pada setiap hukum. Rahasia itu adalah : maqasid al syariah membantu melindungi kepentingan

${ }^{8}$ Ahcene Lahsasna, Maqasid Al Shari'ah In Islamic Finance, hlm. 3 
umat manusia dan mencegah kejahatan, untuk merealisasikan kemanfaatan umum bagi masyarakat, mendorong kebaikan dan menghindari kejahatan.

Maqasid al syariah selanjutnya digunakan untuk menentukan ijtihad. Terdapat 5 modal dasar ijtihad menurut Ibn Ashur ${ }^{9}$, yaitu:

1. Memahami teks secara linguistik, yakni melihat teks dari kacamata bahasa dengan berpegangan pada kaidah-kaidah bahasa serta memahami dalildalil yang menopang teks tersebut. Hampir semua segmen kajian ini telah terwadahi dalam disiplin ilmu ushul fiqh.

2. Mencari teks dan dalil-dalilnya yang lain sekiranya akan terdapat pertentangan antar dalil (ta'arudl al-adillab). Hal ini dilakukan guna meyakinkan teks tersebut selamat dari pertentangan. Dan jika pertentangan tidak bisa dihindari maka dilihat kemungkinan untuk mengamalkan kedua teks. Dan jika tidak memungkinkan maka dimenangkan (ditarjï) salah satu diantara keduanya.

3. Melakukan qiyas, jika satu permasalahan tertentu belum termaktub dalam teks-teks agama yang ada, baik dari alquran ataupun alhadits. Namun hal ini dilakukan dengan prasyarat adanya kejelasan illat bukm(alasan hukum) yang sama berkenaan dengan permasalahan tadi.

4. Melakukan ijtihad untuk menentukan hukum suatu persoalan tertentu yang belum diketemukan sebelumnya, baik karena nihilnya dalil atas teks yang ada atau karena sulitnya melakukan qiyas.

5. Menerima teks apa adanya jika tidak memungkinkan menguak dasar atas pensyariatan suatu hukum tertentu dan tidak pula ditemukan hikmah di balik pensyariatannya itu.

Berdasarkan pendapat Ibn Ashur tersebut, Dr. Acene Lahsasna menyampaikan bahwa maqasid al syariah mempunyai peranan yang signifikan untuk $^{10}$ : 
1. Maqasid al syariah menentukan level maslahah dan mafasid

2. Maqasid al syariah mengidentifikasi tujuan tersembunyi dari hukum yang berlaku dan membantu untuk menentukan keputusan hukum yang tepat.

3. Maqasid al syariah mengidentifikasi penyebab yang mendasari putusan kasus tertentu: ini berhubungan dengan teori penalaran yang merupakan salah satu aspek utama dari maqasid.

4. Maqasid al syariah meminimalkan kesalahan potensi ijtihad, karena kehadiran maqasid akan menampilkan ijtihad yang utuh, akurat dan lebih tepat.

Al-Syatibi membagi Maqashid menjadi tiga tingkatan, yaitu: Maqashid dharuriyat, Maqashid hajiyat,dan Maqashid tahsiniyat. Dharuriyat artinya harus ada demi kemaslahatan hamba, jika tidak ada, akan menimbulkan kerusakan, misalnya rukun Islam. Hajiyatmaksudnya sesuatu yang dibutuhkan untuk menghilangkan kesempitan, seperti rukhsah(keringanan) tidak berpuasa bagi orang sakit. Tahsiniyat artinya sesuatu yang diambil untuk kebaikan kehidupan dan menghindarkan keburukan, semisal akhlak yang mulia, menghilangkan najis, dan menutup aurat ${ }^{11}$.

Dharûriyat jelaskan lebih rinci mencakup lima tujuan, yaitu:

1. Menjaga agama (hifzh al-din);

2. Menjaga jiwa (hifzh al-nafs);

3. Menjaga akal (hifzh al-'aql);

4. Menjaga keturunan (hifzh al-nasl);

5. Menjaga harta (hifzh al-mâl).

Maqasid memiliki peran penting dalam mengembangkan ekonomi dan keuangan Islam. pentingnya peran ini mengacu pada tujuan syariah di bidang keuangan, transaksi bisnis dan tujuan keseluruhan syariah bagi kekayaan. seperti yang telah disebutkan dalam konsep maqashid, pelestarian dan perlindungan kekayaan adalah salah satu tujuan dari syariah, diklasifikasikan dalam kategori daruriyyat.

11 Yubsir, maqâshid al-syari'ahsebagai Metode interpretasi teks hukum: Telaah Filsafat Hukum Islam Al‘Adalah Vol. XI, No. 2 Juli 2013 
Menurut Dr. Ahcene Lahsasna, maslahah merupakan elemen inti dari maqasid al syariah yang menunjukkan arti kebenaran dan kebaikan ${ }^{12}$ yang meliputi maslahah umum dan pribadi.

Nampaknya hal inilah yang menjadi konsep pokok yang ingin dikemukakan oleh Dr. Ahcene Lahsasna, yaitu maslahah dan mafsadah dari perspektif maqasid al syariah.Sebab menurut Dr. Ahcene Lahsasna, sebenarnya seluruh teori maqasid berputar di sekitar pertimbangan maslahah dan mafsadah $^{13}$.Disebutkan kriteria maslahah dan mafsadah dengan mengambil pendapat ibn Ashur sebagai berikut :

1. Sesuatu dimana nilai manfaat atau bahayanya benar-benar ada dan bersifat terus-menerus, seperti mengambil manfaat udara dan sinar matahari atau membakar sebuah kebun dengan tujuan hanya untuk merusaknya.

2. Sesuatu dimana keberadaan manfaat atau pun bahayanya terlihat jelas pada sebagian besar keadaan dan dapat diketahui dengan akal sehat, seperti menyelamatkan orang yang tenggelam di laut.

3. Sesuatu dimana tidak ada kemungkinan untuk tergantikannya sifat manfaat ataupun bahaya yang terdapat di dalamnya. Contohnya di dalam khamrterdapat manfaat yaitu membangkitkan keberanian dan mudharat yaitu merusak akal, hanya saja sisi mudharatnya tetap tidak bisa digantikan dengan sisi kemaslahatannya.

4. Sesuatu dimana nilai manfaat dan bahayanya tampak sama besarnya, namun salah satunya dapat dimenangkan dengan bantuan murajīh seperti kewajiban memberikan ganti rugi atas perusakan harta seseorang dengan sengaja.

5. Sesuatu dimana nilai manfaatnya ada dan tetap sedangkan nilai bahayanya berubah-ubah ataupun sebaliknya, seperti bahaya yang dihasilkan dari 
peminangan seseorang terhadap wanita yang berada dalam pinangan orang lain.

Dengan gambar Dr. Ahcene Lahsasna menjelaskan konsep maslahah mursalah sebagai berikut ${ }^{14}$ :

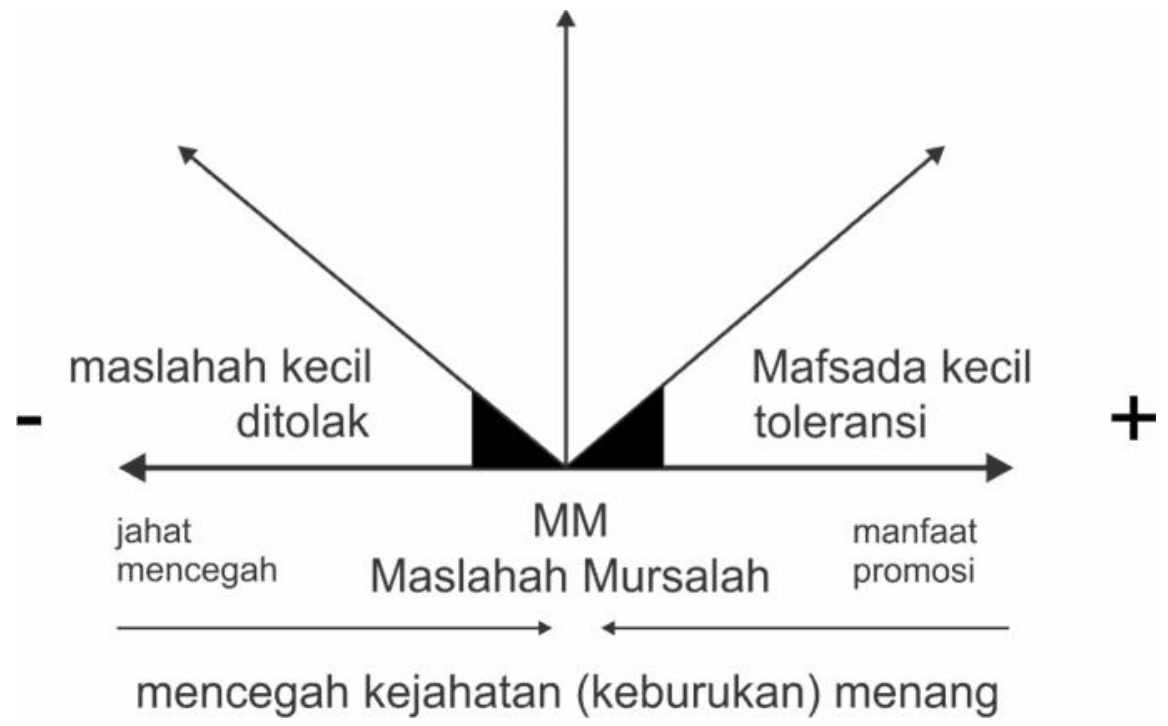

Grafik di atas menunjukkan bagaimana maslahah dan mafsadah harus dipahami dari sudut pandang syariah, dan untuk menentukan ketika konflik terjadi diantara keduanya. sisi positif merupakan maslahah yang diakui oleh pemberi hukum, sedangkan sisi negatif merupakan maslahah yang ditolak oleh pemberi hukum. syariah mempromosikan dan memungkinkan maslahah yang bernilai positif karena adanya manfaat yang direalisasikan, kemudian melarang maslahah yang bernilai negatif karena mengakibatkan kerugian, kerusakan dan kejahatan. adanya maslahah tidak berarti bahwa tidak ada mafsadah sama sekali; Namun, mafsadah yang kecil diabaikan oleh syariah, yang berarti bahwa keberadaan mafsadah kecil tidak menyebabkan gugurnya maslahah disebabkan karena adanya manfaat utama yang lebih besar.

Kemudian, keberadaan mafsadah bukan berarti juga bahwa tidak ada maslahah di dalamnya. Namun maslahah yang kecil tidak cukup untuk menerima mafsadah yang lebih besar. filosofi dasar ini menyebutkan ketika syariah membahas 
maslahah dan mafsadah didasarkan pada argumen bahwa tidak ada maslahah murni atau mafsadah murni, selalu maslahah dikaitkan dengan mafsadah kecil dan mafsadah yang berhubungan dengan maslahah kecil. Namun, syariah memberikan perhatian lebih kepada sisi yang paling besar porsinya, apakah itu maslahah atau mafsadah.

Aplikasi konsep maslahah dalam keuangan Islam misal diterapkan dalam:

1. Menggunakan janji sebagai alat dalam murabahah

2. Menggunakan janji sebagai alat dalam pertukaran mata uang

Namun konsep maslahah cukup sulit diterapkan misal dalam :

1. Berubahnya harga dalam akad istisna

2. Penjadwalan kembali pembayaran murabahah

\section{MAQASID AL SYARIAH DALAM EKONOMI DAN KEUANGAN ISLAM BERDASARKAN PENDEKATAN UMUM}

Sesuai dengan prinsip-prinsip maqasid al syariah, sistem Islam menitikberatkan pada dimensi etika, moral, sosial dan agama, untuk menjamin keadilan, kesetaraan, dan keadilan untuk kebaikan masyarakat secara keseluruhan ${ }^{15}$.

Maka secara umum, maqasid al syariah dalam ekonomi dan keuangan Islam bertujuan untuk :

1. Stabilitas ekonomi, keuangan dan bisnis penyaluran kekayaan melalui sistem keuangan untuk mengembangkan lembaga keuangan, melestarikan kekayaan masyarakat melalui skema deposito di asuransi yang ditawarkan oleh regulator, mengkonversi tabungan menjadi investasi,

2. Memastikan keadilan dalam bisnis dan keuangan 
Untuk itulah kemudian dilakukan pelarangan riba, monopoli, gharar, duress (ikrah), ghalat, ghubn, dan taghrir.

3. Menyuburkan Prinsip Keadilan

4. membangun kontrak / instrumen dalam memperoleh properti dan kekayaan

5. sirkulasi kekayaan dalam sistem keuangan

6. pelestarian dan perlindungan kekayaan

7. hak untuk memiliki dan mendapatkan kekayaan

8. transparansi dalam bisnis dan keuangan

9. dokumentasi di bidang keuangan Islam

10. pembangunan dan investasi kekayaan

11. mencegah bahaya dan kesulitan dalam bisnis dan keuangan

\section{MAQASID AL SYARIAH DALAM EKONOMI DAN KEUANGAN ISLAM BERDASARKAN PENDEKATAN KHUSUS}

Maqasid al syariah dalam keuangan Islam juga memiliki pendekatan khusus berdasarkan pandangan mikro yang terkait dengan transaksi tertentu yang menunjukkan latarbelakang diberlakukannya sebuah hukum. maqasid al syariah akan disorot berdasarkan transaksi keuangan Islam yang berbeda yang ditawarkan di bidang keuangan Islam. Dalam hal ini Dr Ahcene Lahsasna melakukan pendekatan maqasid al syariah dengan melihat aspek maslahah untuk mempertimbangkan sebuah transaksi.

1. Maqasid al syariah di utilitas dan kerja

Dalam hal ini syariah sama-sama ingin melindungi kepentingan sesuai hak, baik pemberi kerja maupun pekerja.

2. Maqasid al syariah dalam kontrak surat berharga

Dalam membahas tentang rahn, Dr Ahcene Lahsasna mengatakan bahwa objek yang digadaikan berada di kreditur dengan tujuan mendorong 
debitur untuk lebih cepat membayar utangnya ${ }^{16}$. tentunya hal seperti itu lebih tepat dari sisi maslahat. Demikian juga dalam membahas tentang urbun, beliau mengatakan bahwa urbun adalah jumlah yang dibayarkan sebagai pengganti hak yang diberikan kepada pembeli untuk memiliki masa tunggu, apakah akan melanjutkan atau menarik diri dari kontrak ${ }^{17}$. Sebuah pernyataan yang memperlihatkan konsep keadilan dalam maslahah mursalah. Berikutnya dalam mengomentari tentang fee kafalah, beliau sepakat dengan pendapat beberapa ulama kontemporer yang berpendapat bahwadiperbolehkannya ijarah dikenakan pada kafalah berdasarkan maslahah dan kebutuhan masyarakat karena dalam konteks saat ini akan menyulitkan dan tidak praktis untuk mendapatkan biaya jaminan yang gratis ${ }^{18}$.

3. Maqasid al syariah dalam kontrak sukarela

Dalam hal ini Dr Ahcene Lahsasna mempermudah penilaian terhadap kontrak sukarela. Nampaknya hal ini karena kontrak jenis ini lebih banyak mendatangkan maslahah. Beliau mengatakan agar diberikan bantuan dan kemudahan dalam kontrak ini, karena bebas dari keuntungan komersial. Sebab tujuan menyediakan kontrak sukarela adalah untuk menghasilkan pahala dan berkah dari Alloh SWT. Bahkan diberikan fleksibilitas dan toleransi pada apa yang dilarang dalam kontrak pertukaran seperti gharar dan lain-lain ${ }^{19}$. Kontrak yang dimaksud adalah 'ariyah, hibah, wadi'ah, waqf, wasiyyah dan tabarru'.

4. Maqasid al syariah dalam mendukung basis transaksi

Dalam pembahasan tentang hawalah, Dr ahcene Lahsasna mengatakan bahwa hawalah merupakan penyelesaian utang yang menggembirakan masyarakat ${ }^{20}$. Berikutnya, beliau mengatakan rentang ibra' sebagai 
bantuan keuangan yang mendorong dan membantu para anggota masyarakat dengan menunjukkan kemurahan dan kebaikan ${ }^{21}$. Kemudian, tentangmuqassah, beliau mengatakan bahwa akad ini akan mendorong bisnis dan perdagangan di pasar ${ }^{22}$. Untuk akad suftajah dikatakan bahwa akad ini mengamankan, melindungi dan melestarikan kekayaan seseorang $^{23}$.

5. Maqasid al syariah di sarana keuangan

Poin penting yang ingin disampaikan adalah bahwa uang adalah alat tukar, bukan sebagai barang yang bisa dijual belikan. Sesuai konsep maslahah, Ibnu Tamiyah dalam kitabnya Majmu' Fatwa Syaikh al-Islām menyampaikan lima butir peringatan penting mengenai uang sebagai komoditi ${ }^{24}$, yakni: 1. Perdagangan uang akan memicu inflasi; 2. Hilangnya kepercayaan orang terhadap stabilitas nilai mata uang akan mengurungkan niat orang untuk melakukan kontrak jangka panjang, dan menzalimi golongan masyarakat yang berpenghasilan tetap seperti pegawai/ karyawan; 3. Perdagangan dalam negeri akan menurun karena kekhawatiran stabilitas nilai uang; 4. Perdagangan internasional akan menurun; 5. Logam berharga (emas dan perak) yang sebelumnya menjadi nilai intrinstik mata uang akan mengalir keluar negeri.

6. Maqasid al syariah dalam perbankkan Islam

Produk perbankkan Islam semakin berkembang. Dalam pembahasan tentang mobilisasi dana dan deposito, Dr Ahcene Lahsasna menyatakan ketika ada potensi kerugian kekayaan deposan atau deposit terkena risiko, langkah syariah adalah melakukan pembatasan transaksi atau memaksakan beberapa kewajiban untuk tujuan mengamankan kepentingan deposan ${ }^{25}$.

${ }^{21}$ Ibid, hlm. 137

${ }^{22}$ Ibid, hlm. 137

${ }^{23} \mathrm{Ibid}$, hlm 138

${ }^{24}$ Muslimin Kara , Uang Dalam Perspektif Ekonomi Islam, Assets Volume 2 Nomor 1 Tahun 2012, hlm. 53

${ }^{25}$ Ahcene Lahsasna, Maqasid Al Shari'ah In Islamic Finance, hal 154 
Ketika berbicara mengenai mudharabah, beliau mengatakan bahwa proses pengungkapan tingkat rata-rata bagi hasil akun mudharabah adalah sejalan dengan maqasid al syariah karena memberikan referensi dan persepsi keseluruhan pada risiko dan pengembalian investasi ${ }^{26}$.

7. Maqasid al syariah di takaful

Mengenai takaful, dikatakan bahwa perlindungan hak milik dari kerusakan dan kehancuran adalah salah satu tujuan maqasid al syariah. Tujuan ini diwujudkan dengan takaful dimana kebijakan takaful adalah untuk menjaga nilai aset ${ }^{27}$. Tentunya hal ini harus bebas dari, gharar, maysir dan riba ${ }^{28}$.

8. Maqasid al syariah di pasar modal Islam

Dalam pasar modal maqasid al syariah diterapkan untuk ${ }^{29}$ :

a. menciptakan pasar, yaitu berupa ekspansi untuk kegiatan yang diizinkan dan ruang halal untuk mempromosikan kebajikan dan mencegah keburukan.

b. membuat jalan bagi investasi syariah dan kegiatan usaha di pasar primer dan pasar sekunder.

c. menciptakan sebuah platform untuk likuiditas.

d. mempertimbangkan jalan untuk membuat keuntungan yang diijinkan dan akumulasi kekayaan.

9. Maqasid al syariah di pasar saham Islam

Dalam salah satu bagian, Dr Ahcene lahsasna menyampaikan tentang pentingnya platform pendidikan untuk pelaku pasar saham guna memunculkan transparansi dan kejujuran. Hal ini untuk menghindari gharar dan ambiguitas, menyesatkan dan salah presentasi dan untuk memungkinkan pedagang mengambil keputusan yang tepat ${ }^{30}$.

${ }^{27}$ Ibid, hlm. 178. Lihat juga Refky Fielnanda. (2017). Konsep Screening Saham Syariah di Indonesia. ALFALAH: Journal of Islamic Economics, 2(2).

${ }^{28} \mathrm{Ibid}, \mathrm{hlm} .179$

${ }^{29}$ Ibid, hlm. 184

${ }^{30}$ Ibid, hlm.190 
10. Maqasid al syariah dalam perencanaan keuangan

Disampaikan oleh Dr. Ahcene Lahsasna bahwa tujuan maqasid al syariah dalam perencanaan keuangan bertujuan untuk ${ }^{31}$ :

1. sirkulasi kekayaan dalam transaksi bisnis melalui perencanaan dan pengelolaan keuangan yang tepat.

2. pelestarian dan perlindungan kekayaan.

3. transparansi dalam kekayaan dan keuangan.

4. pengembangan dan investasi kekayaan.

5. mencegah bahaya dan kesulitan dalam akuisisi kekayaan dan keuangan.

6. memastikan keadilan dalam sirkulasi kekayaan.

Untuk itu diperlukan ${ }^{32}$ :

1. perencanaan resiko dan takaful

2. perencanaan investasi

3. perencanaan zakat

4. perencanaan tempat tinggal

5. perencanaan pensiun

\section{MAQASID AL SYARIAH DAN KAIDAH FIQH}

Dalam buku ini terdapat bab yang menjelaskan tentang kaidah hukum Islam (legalmaxim). Dalam hukum Islam terdapat lima kaidah hukum sebagai berikut $^{33}$ :

1. Segala sesuatu dinilai berdasarkan maksud dan tujuannya

2. Sesuatu yang diyakini tidak bisa digugurkan oleh sesuatu yang meragukan.

3. Kerusakan hendaknya dihilangkan.

4. Situasi berat bisa menghadirkan kelonggaran hukum. 
5. Tradisi setempat bisa menjadi dasar hukum.

Dr. Ahcene Lahsasna nampaknya ingin memberikan penguatan kepada konsep maqasid al syariah dengan menegaskan hubungan yang kuat dan saling membangun antara maqasid al syariah dengankaidah fiqh dalam Islam.

\section{BENTUK DAN SUBSTANSI MAQASID AL SYARIAH DALAM APLIKASI KEUANGAN ISLAM}

Dalam hal ini, Dr. Ahcene Lahsasna ingin menjelaskan tentang bentuk dan substansi penerapan maqasid al syariah. Dalam Islam, setiap transaksi harus terdapat akad didalamnya. Akad yang dilakukan memiliki konsekuensi duniawi dan ukhrawi karena akad yang dilakukan itu berdasarkan Hukum Islam. Dalam Islam, perjanjian tersebut memiliki pertanggung jawaban hingga yaumil qiyāmah ${ }^{34}$.

Dimulai dengan adanya sighah berupa pernyataan yaitu cara untuk membentuk kontrak dalam hukum komersial Islam, dimana masing-masing pihak akan menyampaikan kesediaannya untuk menyepakati kontrak dan menerimanya ${ }^{35}$. Substansi dari bentuk perjanjian ini adalah niat (intention) ${ }^{36}$. Sebab dalam Islam niat mampu merubah aturan syariah yang berlaku ${ }^{37}$. Masalah sekarang adalah bagaimana menentukan niat para pihak dalam transaksi jika tidak ada mengungkapkan niat atau bersedia mengungkapkannya? ini adalah pertanyaan yang sangat penting dan jawabannya tergantung pada beberapa kriteria yang terkait dengan konsekuensi dari tindakan. pembahasan tentang masalah ini terkait dengan sadd al dhara'i yang merupakan salah satu sumber syariah ${ }^{38}$. Dalam hal ini maka sesuatu yang pasti menyebabkan kejahatan, keburukannya lebih banyak dibandingkan kebaikan atau kemungkinan besar menimbulkan keburukan walaupun belum pasti lebih baik ditolak.

\footnotetext{
${ }^{34}$ Muhammad Syafi'i Antonio, Bank Syariah dari Teori ke Praktek, hlm. 29-30

35 Ahcene Lahsasna, Maqasid Al Shari'ah In Islamic Finance, hlm. 257

${ }^{36}$ Ibid, hlm.259

${ }^{37}$ Ibid, hlm.266

${ }^{38} \mathrm{Ibid}, \mathrm{hlm} .269$
} 
I. Akhlak, Maqasid Al Syariah dan Keuangan Islam

Menurut Dr Ahcene Lahsasna salah satu tujuan umum maqasid al syariah adalah untuk membangun prinsip etika dalam setiap aspek kehidupan termasuk dalam ekonomi dan kegiatan usaha ${ }^{39}$. Dalam keuangan Islam, setidaknya terdapat beberapa kode etik yang harus ada yaitu : kebenaran dan kejujuran, integritas, ketulusan, tanggungjawab dan akuntabilitas.

\section{PENUTUP}

Dalam akhir bukunya, Dr Ahcene Lahsasna menyampaikan resolusi untuk perbankkan Islam berdasarkan konsep maqasid al syariah yang dikeluarkan oleh Shari'ah Advisory Council (SAC). Dr Ahcene Lahsasna sepertinya ingin memberikan sebuah penguatan pemahaman bahwa Islam melalui maqasid al syariah mampu diaplikasikan dan akan menghasilkan kebaikan yang istimewa.

Maqasid al syariah merupakan aspek penting dalam pengembangan hukum Islam.Ini sekaligus sebagai jawaban bahwa hukum Islam itu dapat dan bahkan sangat mungkin beradaptasi dengan perubahan-perubahan sosial yang terjadi di masyarakat.Namun Maqasid al syariah (dalam Ushul Fiqh tradisional) selalu dianggap sebagai ilmu pelengkap, bukan sebagai sebuah disiplin ilmu yang independen dalam menetapkan suatu hukum. Dalam hal ini, Dr Ahcene Lahsasna mencoba menerapkan maqasid al syariah untuk menetapkan berbagai ketentuan dalam konsep mengenai keuangan Islam. 


\section{DAFTAR PUSTAKA}

Antonio, Muhammad Syafi'i, Bank Syariah dari Teori ke Praktek. Jakarta : Gema Insani

Auda, Jasser (2008). Maqasid Al-Shariah as a Philosophy of Islamic Law: a System Approach. Washington : the international institute of islamic thought London.

Fielnanda, R. (2017). Konsep Screening Saham Syariah di Indonesia. AL-FALAH: Journal of Islamic Economics, 2(2).

Lahsasna, Ahcene (2013). Maqasid al Shari'ah In Islamic Finance. Kualalumpur : IBFIM

Kara, Muslimin (2012). UANG DALAM PERSPEKTIF EKONOMI ISLAM. ASSETS Volume 2 Nomor 1 Tahun 2012

Kuntowijoyo, (1998). Paradigma Islam Reinterpretasi Untuk Aksi. Bandung : Mizan

Nurrohman, Dede(September 2010). konsep self-interest dan maslahah dalam rasionalitas ekonomi islam. Jurnal ISLAMICA, Vol. 5, No. 1,

Yubsir , (Juli 2013). maqâshid al-syari'ahsebagai Metode interpretasi teks hukum: Telaah filsafat hukum islam AL-'ADALAH Vol. XI, No. 2 